\title{
Chantal Meyer-Plantureux, Antisémitisme et homophobie. Clichés en scène et à l'écran, XIX-XX siècles
}

\section{Francesca Forcolin}

\section{(2) OpenEdition}

\section{Journals}

\section{Edizione digitale}

URL: https://journals.openedition.org/studifrancesi/21874

DOI: 10.4000/studifrancesi.21874

ISSN: 2421-5856

\section{Editore}

Rosenberg \& Sellier

\section{Edizione cartacea}

Data di pubblicazione: 1 décembre 2019

Paginazione: 624-625

ISSN: 0039-2944

\section{Notizia bibliografica digitale}

Francesca Forcolin, «Chantal Meyer-Plantureux, Antisémitisme et homophobie. Clichés en scène et à l'écran, xIx-xx siècles», Studi Francesi [Online], 189 (LXIII | III) | 2019, online dal 01 mars 2020, consultato il 11 novembre 2021. URL: http://journals.openedition.org/studifrancesi/21874 ; DOI: https://doi.org/ 10.4000/studifrancesi.21874

Questo documento è stato generato automaticamente il 11 novembre 2021.

\section{(c) $($ ) $(9)$}

Studi Francesi è distribuita con Licenza Creative Commons Attribuzione - Non commerciale - Non opere derivate 4.0 Internazionale. 


\title{
Chantal Meyer-Plantureux, Antisémitisme et homophobie. Clichés en scène et à l'écran, XIX-XX siècles
}

\author{
Francesca Forcolin
}

\section{NOTIZIA}

Chantal Meyer-Plantureux, Antisémitisme et homophobie. Clichés en scène et à l'écran, XIX-XX siècles, CNRS editions, Paris, 2019, 400 pp.

1 Nella Francia della Terza Repubblica (e non solo), l'Ebreo e l'Omosessuale sono figure turpi, spregevoli, condannate e ripudiate, i capri espiatori di una società scalfita da una profonda crisi dell'identità maschile, fattasi estrema dopo la sconfitta del 1870 dramma nazionale, prova della debolezza di un paese e del collasso della razza. Da questa ferita, l'omofobia erompe come lo strumento sovrano per ristabilire l'ordine e le regole: maschio e femmina, francese e straniero, normale e anormale. A teatro come al cinema, le minoranze vengono sempre più condannate mediante l'esaltazione di stereotipi e caratterizzazioni grottesche. Il timore per tutto ciò che potrebbe definitivamente sgretolare la virilità della nazione, innesca la ridicolizzazione del diverso e la sua messa al bando. Meyer-Plantureux, in questo volume suddiviso in 26 complessi capitoli, ripercorre settant'anni di storia del teatro e del cinema nei suoi caratteri di sfrontato e attualissimo odio verso l'Altro. Nonostante i decreti postrivoluzione francese inneggianti l'uguaglianza tra gli uomini (Ch. 1, «L'apprentissage de la citoyenneté», pp. 17-22), l'antisemitismo prende piede a teatro con Octave Mirbeau, per consolidarsi con la pubblicazione dell'opera di Drumont La France juive, raccolta dei cliché dell'antiebraismo cattolico, che avrà forti ripercussioni sulla vita artistica dell'epoca (Ch. 2, «Naissance de l'antisemitisme culturel», pp. 23-32). C'è un'opera, tuttavia, anomala: L'ami Fritz di Erckmann-Chatrian che, grazie alla presenza di un rabbino stranamente non caricaturato, ma umano nei suoi pregi e difetti, si 
contraddistingue. La mancanza di timore nell'esprimere le proprie radici caratterizza due attori esemplari, Sarah Bernhardt e De Max (Ch. 3, «Etre juif ou homosexuel sans concession à l'antisémitisme et à l'homophobie», pp. 33-44): quest'ultimo diede vita a vari personaggi tratti dall'antichità («Comment parler de l'homosexualité: le detour par l'Antiquité ou la Bible», pp. 45-52). Soggetto di successo in letteratura, meno tabù dell'omosessualità maschile, il rapporto saffico venne tentato a teatro, portando gli autori a scontrarsi con la censura (Ch. 5, "Couvrez ce vice que je ne saurais voir», pp. 53-58). Lontana dall'essere un'apologia dell'omosessualità, l'inizio del Novecento segna la data della prima pièce a cui la censura dà un po' di respiro, Le Monsieur aux chrysantèmes di Armory (Ch. 6, "Le vice errant ou la perception de l'homosexualité au tournant du siècle», pp. 59-68). Se gli omosessuali vengono raffigurati in maniera per lo più ridicola e grottesca, gli ebrei invece appaiono sempre come personaggi spregevoli: essi non scatenano mai l'ilarità, come nelle opere di Lavedan o di Guinon (ch. 7, «La Belle époque de l'antisemitisme», pp. 69-86). E ancora, sulla questione ebraica come minaccia dell'identità cattolica francese verte il capitolo 8 («La réponse des auteurs dramatiques juifs et des auteurs "philosémites"», pp. 87-103); sull'opera teatrale di Rothschild, autore spesso fortemente disprezzato, si concentra il capitolo successivo, «Une tête de turc facile, Henri de Rothschild» (pp. 103-116); la messa in scena dell'Affaire Dreyfus ha il suo esordio con i film di Méliès di impianto realista che conobbero un enorme successo («L'affaire Dreyfus au théâtre et au cinéma: la réhabilitation du juif?», pp. 117-124). Segue «L'Union sacrée au théâtre» (pp. 125-128) incentrato sull'affaire Bernstein; «La politique ambigue de la Comédie-Française autour de la "question juive"» (pp.129-134) sulla rappresentazione contestata della pièce antisemita Le Prince d'Aurec di Lavedan; «La persistance des clichés», analisi generale sulla inevitabile banalizzazione della figura dell'ebreo, in particolare del tipico banchiere. Argomento trattato negli anni Venti è in particolar modo la descrizione delle condizioni di vita nei ghetti e l'emigrazione verso gli Stati Uniti («Juifs persécutés ou juifs révolutionnaires», pp. 145-158); continua a essere di gran moda, invece, la questione omosessuale, con il desiderio di colorire le opere di una vena scandalosa - tra gli autori, impossibile non pensare a Wilde, Proust e Gide («La folle boulevardière ou l'homosexuel condamné», pp. 159-180); e se negli anni Trenta si inasprisce la questione ebraica, tra critiche (Ezechiel di Albert Cohen) e giudizi favorevoli, questi ultimi non condivisi dai circoli ebraici (David Golder di Irène Némirovsky) («Les années 1930 sur scène et à l'écran: ils voient des juifs partout...», pp. 181-200), l'odio antisemita costringe alcuni produttori, tra cui Gabriel Astruc, ad abbandonare la direzione dei teatri («La haine antisémite contre les directeurs, producteurs ou autres intermédiaires juifs», pp. 201-214). In opposizione alle figure di ebrei inquietanti, nel corso degli anni Trenta troviamo alcune commedie che ne smussano i tratti, come la saga dei Lévy di André Hugon («L'antisémitisme "bon enfant”: Hugon, Gréville, Vautel et les autres», pp. 215-222). E se nella diffusione dell'antisemitismo e dell'omofobia è particolarmente importante il ruolo giocato dalla critica teatrale e cinematografica, la voce dei critici si riduce fino a sparire con la Seconda Guerra Mondiale («Qui sont les critiques?», pp. 223-230), nonostante vigano ancora alcune prese di posizione («La critique aux ordres», pp. 231-244). Alcune pièces - a firma di Brecht, Bruckner e Tchirikoff - avevano messo in guardia contro i pericoli del nazismo («La Collaboration sans peine», pp. 245-252); sotto l'Occupazione, ad eccezione dei film di propaganda, le "silhouttes israélites" che popolavano i corti e lungometraggi, iniziano ad affievolirsi («Divertir avant tout: le cinéma sous l'Occupation», pp. 253-256). Il capitolo 23, «Protégés ou dénoncés: la 
loterie des amitiés» (pp. 257-276), si sofferma su un ulteriore aspetto della questione ebraica: la denuncia con conseguente arresto o deportazione di attori e attrici, delazioni dall'effetto boomerang con la Liberazione («Une épuration à la carte», pp. 277-288), anche se le sanzioni furono spesso troppo leggere se non inique («Les nouveaux maîtres», pp. 289-292). Chiude il volume «Un après-guerre dénué d'antisémitisme et d'homophobie?» (pp.293-307), analisi delle legislazioni del dopoguerra che condannano gli atti discriminatori nei confronti degli ebrei, pur continuando a esigere - e addirittura in forma più tagliente e dettagliata - sanzioni penali per reprimere l'omosessualità. 